\title{
Concerns for management of STEMI patients in the COVID-19 era: a paradox phenomenon
}

\author{
Panayotis K. Vlachakis ${ }^{1}$ - Anastasios Tentolouris ${ }^{2}$ (]) - Ioannis Kanakakis ${ }^{1}$
}

Published online: 30 July 2020

(c) Springer Science+Business Media, LLC, part of Springer Nature 2020

\begin{abstract}
The pandemic of coronavirus disease 2019 (COVID-19) has become a public health emergency of international concern. During this time, the management of people with acute coronary syndromes (ACS) and COVID-19 has become a global issue, especially since preexisting cardiovascular disease is a risk factor for the presence and the severity of COVID-19. The number of people with ST- elevation myocardial infarction (STEMI) has decreased during the pandemic and delays in the time looking for medical care have been reported. In addition, the diagnosis of ACS may have been difficult due to possible underlying myocarditis or other clinical entities. Regarding management of people with STEMI, although the superiority of primary percutaneous coronary intervention (PCI) over thrombolysis is well established, the notable exposure risks due to absence of negative pressure in catheterization rooms and the increased difficulty in fine manipulation on guidewires under proper protection equipment may contribute to the relatively secondary role of PCI during the COVID-19 pandemic; thus, fibrinolytic therapy or robotic-assisted PCI in early presenting STEMI patients may have an alternative role during this period if prevention measures cannot be taken. Healthcare stuff should take the proper measures to avoid the spread of and their exposure to the virus.
\end{abstract}

Keywords COVID-19 · STEMI - Acute myocardial infarction · Acute coronary syndrome $\cdot$ Thrombolysis $\cdot$ Percutaneous coronary intervention

\section{Highlights}

- Cardiovascular disease is associated with increased severity of COVID-19.

- The number of people with STEMI has decreased during the pandemic and delays in the time looking for medical care have been reported.

- The diagnosis of acute coronary syndromes may have been difficult due to possible underlying myocarditis or other clinical entities.

Anastasios Tentolouris

antentol@med.uoa.gr

1 Department of Clinical Therapeutics, School of Medicine, National and Kapodistrian University of Athens, Alexandra General Hospital, Athens, Greece

2 First Department of Propaedeutic Internal Medicine, Medical School, National and Kapodistrian University of Athens, Laiko General Hospital, 17 Agiou Thoma St, 11527 Athens, Greece
- Fibrinolytic therapy or robotic-assisted PCI in early presenting STEMI patients may have an alternative role during this period if prevention measures cannot be taken.

In the end of 2019, a novel RNA coronavirus was identified as the causative pathogen of a highly spread viral pneumonia [1]. The virus was named severe acute respiratory syndrome coronavirus 2 (SARS-CoV-2) and the viral infection was named Coronavirus disease of 2019 (COVID-19). The World Health Organization (WHO), in the middle of March 2020, announced that the world is facing a pandemic situation, since more than $13,378,853$ people have been affected globally and more than 580,045 deaths have been reported [2].

Coronary heart disease (CHD) contributes to one-third of all deaths in individuals over the age of 35, despite the fact that recent data have shown a reduction in mortality rates over the past four decades due to advances in the management of these patients [3, 4]. People who experience a myocardial infarction (MI) may have either ST- elevation myocardial infarction (STEMI) or non-ST elevation acute 
coronary syndrome (ACS), which contains non-ST elevation myocardial infarction (NSTEMI) or unstable angina [5].

Several studies from China demonstrated that patients with prior cardiovascular (CV) disease may be more susceptible to severe or fatal infection from SARS-CoV-2 [6-8]. It is already known that SARS-CoV-2 may affect directly or indirectly the heart, resulting in various clinical manifestations such as myocardial injury, myocarditis, ACS, cardiac arrhythmias, heart failure or cardiogenic shock [9, 10]. Physicians around the world, have recognized a new phenomenon; there are fewer STEMI patients presenting at the hospitals during the pandemic. Data from 9 high volume [ $>100$ primary percutaneous coronary intervention (PCI) per year] cardiac catheterization laboratories in the USA confirmed an estimated reduction of 38\% in STEMI presentation (mean activation per month before vs. after COVID-19 period, 23.6 vs. 15.3 respectively, $95 \%$ CI $26,49, \mathrm{p}<0.001$ ) in the context of sudden COVID-19 outbreak [11]. A similar drop of $40 \%$ in STEMI admissions was observed by RodriguezLeor et al. in Spain [12]. In our public tertiary hospital "Department of Clinical Therapeutics", we compared the number of admissions for ACS during the same calendar period (from March 1 to March 31) in 2019 and in 2020; we found a 30\% reduction (20 cases in 2019 and 14 cases in 2020 ) in ACS admissions. Of note, a 52\% reduction (from 25 cases in 2019 to 12 cases in 2020) in primary PCI was noticed; the vast majority concerned patients suffering from STEMI (unpublished data). However, previous studies have shown that ACS and CV mortality are increased during influenza seasons $[13,14]$ or after acute infection $[15,16]$ due to increased inflammation that leads to destabilization of vulnerable coronary atherosclerotic plaques. Type II MI could be explained by increased wall stress and tachycardia, mainly due to hypoxemia, and type I MI-rapture of atherosclerotic plaque could be attributed to increased release of inflammatory cytokines and thrombophilia [16]. Concerns have been raised that patients with symptoms of cardiac disease, such as MI, may be unwilling to expose themselves to potential infection, so they avoid attendance at hospitals and hence they are searching for care later at the emergency departments or are not presenting at all. This concern was confirmed in a single center study in Hong Kong that compared 7 patients with STEMI presented between January 25th to February 10th of 2020 with 108 STEMI patients treated with PCI 2 years ago, and detected delay in STEMI care times [17]. The study showed that time of symptoms' onset to first medical contact was numerically longer in STEMI patients during COVID -19 era compared to STEMI patients 2 years ago [318 min vs. $82 \mathrm{~min}$ (office hours) and $91.5 \mathrm{~min}$ (non-office hours), respectively]. Delay was also detected in door-to-device [110 $\mathrm{min}$ vs. $84.5 \mathrm{~min}$ (office hours)] and catheterization lab to device times [33 min vs. 20.5 min (office hours)], respectively [17]. Another theory that may explain the lower rates of ACS during COVID-19 pandemic is a possible reduction of smoking, since even though data are limited, current evidence suggests that smoking is most likely associated with more severe disease and adverse outcomes of COVID-19 [18], and lots of people may have quitted smoking. In 2005, the authors of Global Registry of Acute Coronary Events (GRACE) proved that the incidence of STEMI was shown to be higher in smokers compared to former smokers $(46.0 \%$ vs. $27.4 \%, \mathrm{p}<0.001)$ [19]. Another hypothesis worth considering is that staying home reduces stress levels and therefore, the appearance of STEMI.

In the COVID-19 era, clinicians confront a dilemma regarding the optimal management of STEMI patients who alongside may be affected by SARS-CoV-2. The first step is the diagnosis of an acute thrombotic coronary occlusion. In a case report from China, a 37-year-old man presented to the emergency department with symptoms and electrocardiogram (ECG) abnormalities suggesting a possible STEMI [20]. An urgent Computed Tomography coronary angiogram was performed, but no signs of coronary stenosis were revealed. The coronavirus nucleic acid test was positive and the patient was treated as fulminant myocarditis with corticosteroids and immunoglobulin [20]. Similarly, a recently published case report presented a 83-yearold woman who was admitted to the hospital in Geneva due to substernal pain and mild dyspnea for 3 days; she had ST-segment elevation on the ECG with increased level of high sensitive cardiac troponin but no stenosis in coronary angiogram was detected [21]. Concomitant ventriculography was performed and images typical of Takotsubo syndrome were revealed; despite a negative nasopharyngeal swab for SARS-CoV-2, the initial positive immunoglobulin A and negative immunoglobulin G suggested that the patient had recent SARS-CoV-2 infection [21]. A recent case series from New York City, reported that among 18 patients with STEMI and confirmed COVID19 infection, 10 patients (56\%) had non acute thrombotic coronary occlusion; a total of 13 patients $(72 \%)$ died in the hospital, indicating a possible correlation of STEMI and poor prognosis [22]. A possible alternative diagnosis such as viral myocarditis or stress cardiomyopathy due to SARS-CoV-2 should be carefully considered by the physicians.

Another question of importance is whether the fibrinolytic therapy in early presenting (within $3 \mathrm{~h}$ ) STEMI patients may play a leading role during the pandemic. The superiority of PCI over thrombolysis in STEMI cases is well established $[23,24]$. However, the notable exposure risks due to absence of negative pressure in catheterization rooms and the considerable increased difficulty in fine manipulation on guidewires under the proper protection equipment may all contribute to relatively secondary role of PCI during the 


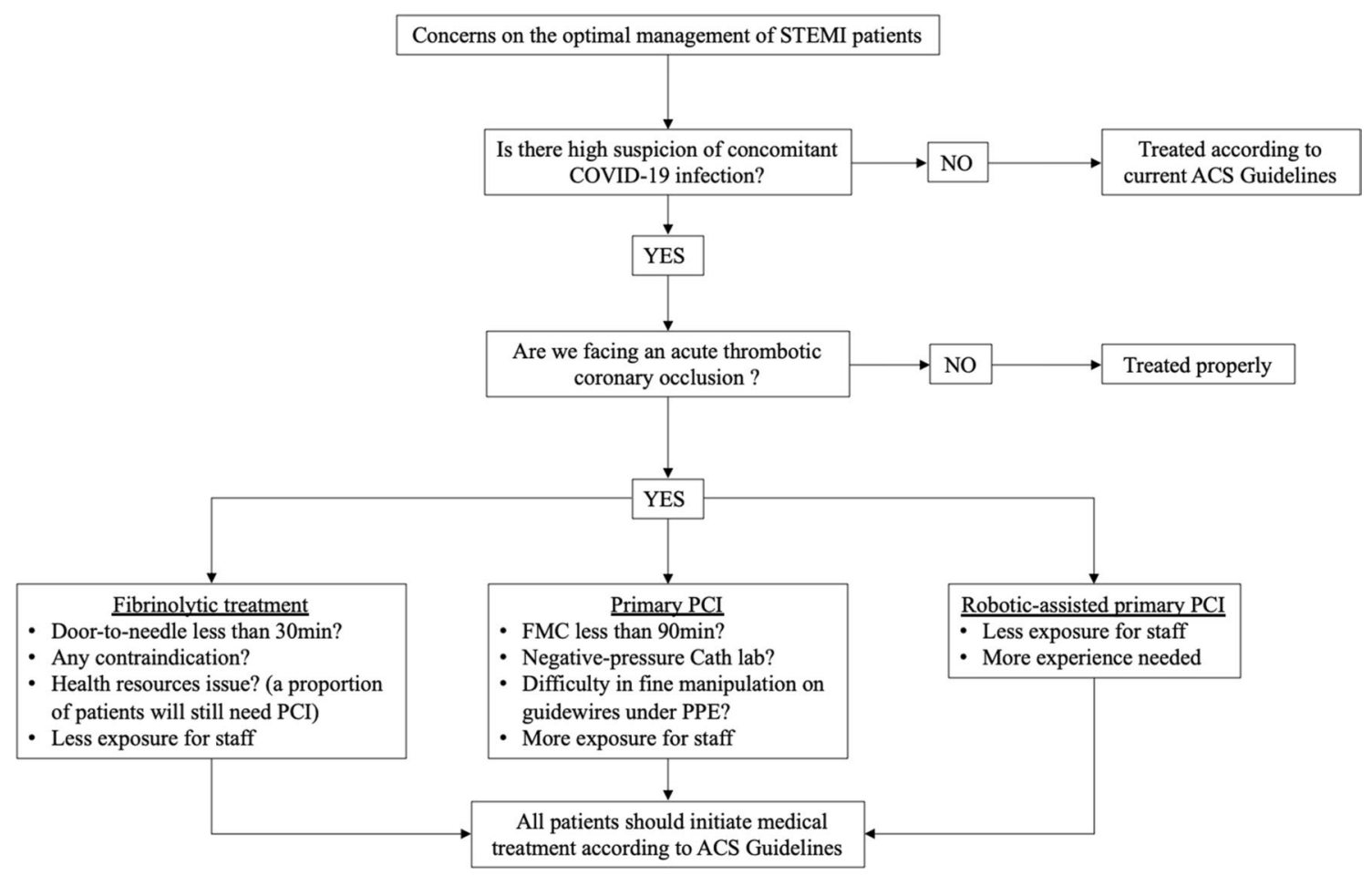

Fig. 1 Concerns for management of suspected STEMI patients with potential risk of COVID-19 infection. ACS, Acute Coronary Syndrome; Cath lab, catheterization laboratory; COVID-19, coronavirus

COVID-19 pandemic [25]. In 2013, the Strategic Reperfusion Early after Myocardial Infarction (STREAM) study demonstrated that the use of fibrinolytic strategy in patients with STEMI who presented within $3 \mathrm{~h}$ after symptoms onset and were not capable for a primary PCI within $1 \mathrm{~h}$, was at least as effective as in those undergoing primary PCI regarding to the composite of death, shock, congestive heart failure or reinfarction up to 30 days $(12.4 \%$ vs. $14.3 \%$ respectively, $\mathrm{p}=0.21$ ) [26]. To date, due to system delays in diagnostic evaluation of patients with STEMI (contact history, diagnostic workup, delay in the preparation of the catheterization staff), it seems that a door-to-needle time of $30 \mathrm{~min}$ in the emergency departments may be a more attainable target than a door-to-balloon time of $90 \mathrm{~min}$ in the catheterization laboratory room [27]. A recently published algorithm for the management of STEMI during SARS-CoV-2 outbreak from "The COVID-19 and Acute Myocardial Infarction (AMI) committee of Peking Union Medical College Hospital" suggested a more leading role of fibrinolytic treatment in STEMI patients with confirmed or suspected COVID-19, in order to achieve the principle of "time is muscle" [28]. On the other hand, an important issue to consider is that using fibrinolytic strategy may not be suitable for all patients, not only due to numerical contraindications, but also because a proportion of them may still need a PCI; something that disease 2019; FMC, first medical contact; PCI; percutaneous coronary intervention; PPE, proper protection equipment

may have an impact on health resources. Another promising idea is the use of robotic-assisted PCI in STEMI patients during SARS-CoV-2 outbreak, as the exposure risk of the catheterization laboratory staff may be reduced [29]. Further randomized trials are needed to demonstrate the safety and efficacy of robotic-assisted PCI against manual PCI, in order to change the current clinical practice. Figure 1 summarizes the considerations when treating a STEMI patient with a possible concomitant COVID-19 infection.

In conclusion, during the pandemic COVID-19, patients having symptoms suggesting of ACS should be searching for medical care directly and be treated properly. Further studies are needed to examine the reason why the number of people with STEMI in the hospitals decreases during the pandemic. From their point of view, physicians and paramedical staff should provide proper health care taking precautions to avoid the spread of and their exposure to the virus.

Funding None.

\section{Compliance with ethical standards}

Conflicts of interest All authors declare that they have no conflict of interest. 


\section{References}

1. Wang C, Horby PW, Hayden FG, Gao GF (2020) A novel coronavirus outbreak of global health concern. Lancet 395(10223):470 473. https://doi.org/10.1016/S0140-6736(20)30185-9

2. WHO (2020) WHO. Coronavirus disease 2019 (COVID-19) situation report-178. https://www.who.int/docs/default-source/coron aviruse/situation-reports/20200716-covid-19-sitrep-178.pdf?sfvrs $\mathrm{n}=28$ ee165b_2. Assessed 17 July 2020

3. Benjamin EJ, Virani SS, Callaway CW, Chamberlain AM, Chang AR, Cheng S, Chiuve SE, Cushman M, Delling FN, Deo R, de Ferranti SD, Ferguson JF, Fornage M, Gillespie C, Isasi CR, Jimenez MC, Jordan LC, Judd SE, Lackland D, Lichtman JH, Lisabeth L, Liu S, Longenecker CT, Lutsey PL, Mackey JS, Matchar DB, Matsushita K, Mussolino ME, Nasir K, O'Flaherty M, Palaniappan LP, Pandey A, Pandey DK, Reeves MJ, Ritchey MD, Rodriguez CJ, Roth GA, Rosamond WD, Sampson UKA, Satou GM, Shah SH, Spartano NL, Tirschwell DL, Tsao CW, Voeks JH, Willey JZ, Wilkins JT, Wu JH, Alger HM, Wong SS, Muntner P, American Heart Association Council on E, Prevention Statistics C, Stroke Statistics S (2018) Heart disease and stroke statistics-2018 update: a report from the American Heart Association. Circulation 137(12):e67-e492. https://doi. org/10.1161/CIR.0000000000000558

4. Ford ES, Ajani UA, Croft JB, Critchley JA, Labarthe DR, Kottke TE, Giles WH, Capewell S (2007) Explaining the decrease in U.S. deaths from coronary disease, 1980-2000. N Engl J Med 356(23):2388-2398. https://doi.org/10.1056/nejmsa053935

5. Thygesen K, Alpert JS, Jaffe AS, Chaitman BR, Bax JJ, Morrow DA, White HD, Group ESCSD (2019) Fourth universal definition of myocardial infarction (2018). Eur Heart J 40(3):237269. https://doi.org/10.1093/eurheartj/ehy462

6. Guan WJ, Ni ZY, Hu Y, Liang WH, Ou CQ, He JX, Liu L, Shan H, Lei CL, Hui DSC, Du B, Li LJ, Zeng G, Yuen KY, Chen RC, Tang CL, Wang T, Chen PY, Xiang J, Li SY, Wang JL, Liang ZJ, Peng YX, Wei L, Liu Y, Hu YH, Peng P, Wang JM, Liu JY, Chen Z, Li G, Zheng ZJ, Qiu SQ, Luo J, Ye CJ, Zhu SY, Zhong NS, China Medical Treatment Expert Group for C (2020) Clinical characteristics of coronavirus disease 2019 in China. N Engl J Med. https://doi.org/10.1056/NEJMoa2002032

7. Wu C, Chen X, Cai Y, Xia J, Zhou X, Xu S, Huang H, Zhang L, Zhou X, Du C, Zhang Y, Song J, Wang S, Chao Y, Yang Z, Xu J, Zhou X, Chen D, Xiong W, Xu L, Zhou F, Jiang J, Bai C, Zheng J, Song Y (2020) Risk factors associated with acute respiratory distress syndrome and death in patients with coronavirus disease 2019 pneumonia in Wuhan, China. JAMA Intern Med. https://doi.org/10.1001/jamainternmed.2020.0994

8. Wang D, Hu B, Hu C, Zhu F, Liu X, Zhang J, Wang B, Xiang H, Cheng Z, Xiong Y, Zhao Y, Li Y, Wang X, Peng Z (2020) Clinical characteristics of 138 hospitalized patients with 2019 novel coronavirus-infected pneumonia in Wuhan, China. JAMA. https://doi.org/10.1001/jama.2020.1585

9. Driggin E, Madhavan MV, Bikdeli B, Chuich T, Laracy J, Bondi-Zoccai G, Brown TS, Nigoghossian C, Zidar DA, Haythe J, Brodie D, Beckman JA, Kirtane AJ, Stone GW, Krumholz HM, Parikh SA (2020) Cardiovascular considerations for patients, health care workers, and health systems during the coronavirus disease 2019 (COVID-19) pandemic. J Am Coll Cardiol. https://doi.org/10.1016/j.jacc.2020.03.031

10. Vlachakis PK, Tentolouris A, Tousoulis D, Tentolouris N (2020) Current data on the cardiovascular effects of the COVID19. Hell J Cardiol. https://doi.org/10.1016/j.hjc.2020.04.001
11. Garcia S, Albaghdadi MS, Meraj PM, Schmidt C, Garberich R, Jaffer FA, Dixon S, Rade JJ, Tannenbaum M, Chambers J, Huang PP, Henry TD (2020) Reduction in ST-segment elevation cardiac catheterization laboratory activations in the United States during COVID-19 pandemic. J Am Coll Cardiol. https:// doi.org/10.1016/j.jacc.2020.04.011

12. Rodriguez-Leor O (2020) Impacto de la pandemia de COVID19 sobre la actividad asistencial en cardiología ntervencionista en España. REC Interv Cardiol 2:82-89

13. Madjid M, Miller CC, Zarubaev VV, Marinich IG, Kiselev OI, Lobzin YV, Filippov AE, Casscells SW 3rd (2007) Influenza epidemics and acute respiratory disease activity are associated with a surge in autopsy-confirmed coronary heart disease death: results from 8 years of autopsies in 34,892 subjects. Eur Heart J 28(10):1205-1210. https://doi.org/10.1093/eurheartj/ehm035

14. Nguyen JL, Yang W, Ito K, Matte TD, Shaman J, Kinney PL (2016) Seasonal influenza infections and cardiovascular disease mortality. JAMA Cardiol 1(3):274-281. https://doi.org/10.1001/ jamacardio.2016.0433

15. Kwong JC, Schwartz KL, Campitelli MA, Chung H, Crowcroft NS, Karnauchow T, Katz K, Ko DT, McGeer AJ, McNally D, Richardson DC, Rosella LC, Simor A, Smieja M, Zahariadis G, Gubbay JB (2018) Acute myocardial infarction after laboratoryconfirmed influenza infection. N Engl J Med 378(4):345-353. https://doi.org/10.1056/NEJMoa1702090

16. Corrales-Medina VF, Madjid M, Musher DM (2010) Role of acute infection in triggering acute coronary syndromes. Lancet Infect Dis 10(2):83-92. https://doi.org/10.1016/S1473 $-3099(09) 70331-7$

17. Tam CF, Cheung KS, Lam S, Wong A, Yung A, Sze M, Lam YM, Chan C, Tsang TC, Tsui M, Tse HF, Siu CW (2020) Impact of coronavirus disease 2019 (COVID-19) outbreak on ST-segment-elevation myocardial infarction care in Hong Kong, China. Circ Cardiovasc Qual Outcomes. https://doi.org/10.1161/circo utcomes.120.006631

18. Vardavas CI, Nikitara K (2020) COVID-19 and smoking: a systematic review of the evidence. Tob Induc Dis 18:20. https:// doi.org/10.18332/tid/119324

19. Himbert D, Klutman M, Steg G, White K, Gulba DC, Investigators G (2005) Cigarette smoking and acute coronary syndromes: a multinational observational study. Int J Cardiol 100(1):109_ 117. https://doi.org/10.1016/j.ijcard.2004.10.004

20. Hu HMF, Wei X, Fang Y (2020) Coronavirus fulminant myocarditis treated with glucocorticoid and human immunoglobulin. Eur Heart J. https://doi.org/10.1093/eurheartj/ehaa190/5807656

21. Meyer P, Degrauwe S, Delden CV, Ghadri JR, Templin C (2020) Typical takotsubo syndrome triggered by SARS-CoV-2 infection. Eur Heart J. https://doi.org/10.1093/eurheartj/ehaa306

22. Bangalore S, Sharma A, Slotwiner A, Yatskar L, Harari R, Shah B, Ibrahim H, Friedman GH, Thompson C, Alviar CL, Chadow HL, Fishman GI, Reynolds HR, Keller N, Hochman JS (2020) ST-segment elevation in patients with Covid-19-a case series. N Engl J Med. https://doi.org/10.1056/NEJMc2009020

23. Andersen HR, Nielsen TT, Rasmussen K, Thuesen L, Kelbaek H, Thayssen P, Abildgaard U, Pedersen F, Madsen JK, Grande P, Villadsen AB, Krusell LR, Haghfelt T, Lomholt P, Husted SE, Vigholt E, Kjaergard HK, Mortensen LS, Investigators D (2003) A comparison of coronary angioplasty with fibrinolytic therapy in acute myocardial infarction. N Engl J Med 349(8):733-742. https://doi.org/10.1056/NEJMoa025142

24. Keeley EC, Boura JA, Grines CL (2003) Primary angioplasty versus intravenous thrombolytic therapy for acute myocardial infarction: a quantitative review of 23 randomised 
trials. Lancet 361(9351):13-20. https://doi.org/10.1016/S0140 $-6736(03) 12113-7$

25. Zhang L, Fan Y, Lu Z (2020) Experiences and lesson strategies for cardiology from the COVID-19 outbreak in Wuhan, China, by 'on the scene' cardiologists. Eur Heart J. https://doi. org/10.1093/eurheartj/ehaa266

26. Armstrong PW, Gershlick AH, Goldstein P, Wilcox R, Danays T, Lambert Y, Sulimov V, Rosell Ortiz F, Ostojic M, Welsh RC, Carvalho AC, Nanas J, Arntz HR, Halvorsen S, Huber K, Grajek S, Fresco C, Bluhmki E, Regelin A, Vandenberghe K, Bogaerts K, Van de Werf F, Team SI (2013) Fibrinolysis or primary PCI in ST-segment elevation myocardial infarction. N Engl J Med 368(15):1379-1387. https://doi.org/10.1056/NEJMoa1301092

27. Daniels MJ, Cohen MG, Bavry AA, Kumbhani DJ (2020) Reperfusion of STEMI in the COVID-19 era-business as usual? Circulation. https://doi.org/10.1161/CIRCULATIO NAHA.120.047122
28. Jing ZC, Zhu HD, Yan XW, Chai WZ, Zhang S (2020) Recommendations from the Peking Union Medical College Hospital for the management of acute myocardial infarction during the COVID-19 outbreak. Eur Heart J. https://doi.org/10.1093/eurhe artj/ehaa258

29. Wegermann ZK, Swaminathan RV, Rao SV (2019) Cath Lab Robotics: paradigm change in interventional cardiology? Curr Cardiol Rep 21(10):119. https://doi.org/10.1007/s 1188 6-019-1218-5

Publisher's Note Springer Nature remains neutral with regard to jurisdictional claims in published maps and institutional affiliations. 